INOVAÇÃo

\title{
É POSSÍVEL UMA ORGANIZAÇÃO E REPRESENTAÇÃO DO CONHECIMENTO SEM PARTIDOS?
}

\author{
Aline Elis Arboit \\ Doutorado em Ciência da Informação - Universidade Estadual Paulista Júlio de Mesquita Filho, UNESP.
}

\section{Resumo}

Trata-se de uma reflexão sobre a concepção social e ideológica da consciência e do conhecimento, sobretudo aquele impresso nos documentos. Busca inspiração no atual debate ocorrido no contexto brasileiro em torno das manifestações ligadas ao movimento "Escolas sem partido" que defende a não doutrinação ideológica durante o processo de transmissão do conhecimento nas escolas. Postula-se que o conhecimento registrado nos livros, apostilas ou demais documentos não é possível de ser transmitido para os alunos, sem interpretação da visão de mundos dos autores e dos professores dos seus respectivos contextos históricos e sociais, nem tampouco organizado e representado isentando as diversas posturas envolvidas: do autor, do leitor e do próprio profissional responsável pela mediação do conhecimento. Mais do que partidária e não neutra, defende-se uma organização representação do conhecimento democrática, pluripartidária e polifônica.

\section{Palavras-chave}

Organização e representação do conhecimento (ORC). Ideologia. Pluralismo.

\section{A KNOWLEDGE ORGANIZATION AND REPRESENTATION IS POSSIBLE WITHOUT PARTIES?}

\begin{abstract}
It is a reflection on the social and ideological conception of consciousness and knowledge, especially those printed in documents. Seeks inspiration in the current debate at the Brazilian context surrounding the events connected with the 'non-party schools' that advocates non-ideological indoctrination during the process of transmission of knowledge in schools. We postulate that the knowledge recorded in the books, brochures or other documents can't be transmitted to students without interpretation of the world's view of authors and teachers of their historical and social contexts, nor organized and represented exempting various positions involved: the author, the reader and the professional himself responsible for the mediation of knowledge. More than partisan and not neutral, we defend an organization representing the democratic knowledge, multi-party and polyphonic.
\end{abstract}

\section{Keywords}

Organization and knowledge representation (ORC). Ideology. Pluralism. 


\section{INTRODUÇÃO}

Observa-se que os enfoques culturais, políticos, sociológicos e éticos cada vez mais têm conquistado espaço nas discussões e estudos sobre as atividades de organização e representação do conhecimento. Haja vista o amplo acolhimento destas noções no domínio em questão (BARITÉ, 2001; OLSON, 2001; BEGHTOL, 2002; 2005; HJØRLAND, 2003; 2008; GUIMARÃES, 2006; LÓPEZ-HUERTAS, 2008; GARCÍA GUTIÉRREZ, 2011; HANSSON, 2013).

Diante desse panorama, verifica-se como necessário o entendimento dos contextos de produção e uso, por serem determinantes para o desenvolvimento das atividades voltadas para organização e representação do conhecimento. O profissional que atua nesse domínio é levado a estabelecer uma relação dialógica com os sujeitos produtores de conhecimento, bem como sua comunidade usuária. Para que essa relação se efetive de fato, considera-se que não há como o profissional manter uma postura neutra, sobretudo em relação à realidade social. Essa necessidade exige do profissional uma postura voltada para mediação de diversas visões de mundo.

Buscando inspiração no atual debate promovido pelo movimento "Escolas sem partido", este artigo procura refletir sobre a concepção social e ideológica da consciência e do conhecimento, sobretudo aquele impresso nos documentos, bem como seus desdobramentos nas atividades de organização e representação do conhecimento. O movimento em questão defende a não doutrinação ideológica durante o processo de transmissão do conhecimento nas escolas por meio da obrigatoriedade da adoção de uma postura neutra do professor em relação à realidade social.

Para subsidiar a discussão, recorre-se principalmente às noções bakhtinianas de linguagem, consciência, dialogismo, alteridade, polifonia, cronotopo e ideologia para compreender o caráter social e permeável do conhecimento, sua relação dialética com a informação e com a realidade social. A partir dessa perspectiva, reflete-se sobre a postura a ser adotada pelo profissional que atua no domínio de Organização e Representação do Conhecimento (ORC).

\section{CONSCIÊNCIA, CONHECIMENTO E VIDA SOCIAL}

Não diferente da consciência, o conhecimento, seja aquele já registrado ou registrável, inevitavelmente sofre influências do seu contexto de construção. Tais interferências são 
intrínsecas à própria natureza dinâmica e porosa do conhecimento, sempre alinhadas e alinhavadas pelos sujeitos aos fatos ocorridos na realidade social.

Um pensamento, uma opinião, um discurso, um texto, uma ideia, um conceito e até mesmo um raciocínio não são produzidos em um mundo complemente abstrato. Tudo implica nos sentidos, nas motivações e nas finalidades para as quais tais elementos são construídos. Nesse sentido, torna-se difícil tratar razão, ideologia, ética, emoção e estética como departamentos completamente apartados entre si. Já dizia o jovem Bakhtin (2010, p.79) que "aquele que pensa teoricamente, contempla esteticamente e age eticamente".

Por mais que se queira tentar separar a teoria da prática, o mundo das ideias do mundo social, a ciência da sociedade ou a razão da ética e da estética ignora-se o fato de que nestas esferas existe sempre um sujeito que buscando alinhavar a seu modo diferentes aspectos destes mundos. Esse sujeito dotado de consciência, no entanto, não se trata de um ser absolutamente individual, mas de um sujeito ao mesmo tempo social, único, insubstituível e sem desculpa para não existir e atuar no mundo. Nesse sentido recorrer-se novamente à Bakhtin (2010, p. 58-59) quando afirma que a "razão teórica em sua totalidade não é senão um momento de razão prática, isto é, da razão decorrente da direção moral de um sujeito único no evento do existir singular".

Com toda a vênia a Descartes, considera-se que um sujeito não pensa somente porque existe, pensa porque também coexiste, porque convive com outros, porque age e se comunica junto e para aos demais. Sua consciência, com efeito, não é construída de modo automático; É construída a partir da incessante interação do sujeito com outrem. Tal concepção assume como base os conceitos marxistas de materialismo dialético e materialismo histórico, engajados aos conceitos bakhtinianos de dialogismo, alteridade, polifonia, cronotopo e ideologia.

A consciência e o conhecimento são materiais ou concretos - não no sentido dicionarizado das palavras - porque são objetivos, pois são produtos da interação do sujeito com os demais na sociedade. São reflexos dos fatos, mudanças, épocas, usos, costumes e conflitos sociais, e são, portanto, dialéticos e históricos. Por isso, a defesa marxista da ineficácia da teoria ou da ciência se não for vista como parte da prática e um desdobramento da realidade social.

O dialogismo, por sua vez, depende da alteridade do sujeito na medida em que este transcende sua identidade em busca de novas visões. Somente por meio do contato com o outro, torna-se possível ao sujeito ver o que ele próprio não consegue em relação a si mesmo. 
Isso ocorre devido à posição de exterioridade ocupada pelo outro em relação sujeito ou vice-versa. Atenta-se, portanto, para duplicidade presente no sujeito: as situações sociais das quais participa fazem com que o sujeito axiologicamente opte ou não por uma transformação do "eu", porque esse "eu" existe sempre em relação aos "outros" de modo tão indissociável que não é possível delimitá-los completamente. No romance "O duplo" citado por Bakhtin em sua obra, Dostoievski ilustra bem a presença do "outro" no sujeito e sua relação com "eu". Conforme o romancista, quanto mais harmoniosa se da relação eu-outro interiormente, melhor para o sujeito, ao passo que a tentativa de descolamento desses dois eixos provoca o seu desequilíbrio, porque para Dostoievski também é inegável o fato de que o "eu” só existe com referência ao "outro".

O termo polifonia foi emprestado do campo da música, onde nas orquestras sinfônicas cada instrumento tem um som distinto e cada um participa à sua maneira integrando o conjunto das execuções musicais (BAKHTIN, 2011). O autor do romance, portanto, passa a ser visto como um regente das vozes de suas personagens, assim como o maestro rege a orquestra. E essas vozes são também vozes sociais, uma vez que o romance reflete a percepção que o seu criador tem do mundo.

Por se referir à equipolência de vozes, a polifonia acarreta necessariamente ao dialogismo existente na linguagem. As vozes sociais, em função das visões de mundo as compõem, atribuem diversos significados às palavras, conferindo à linguagem desse modo uma dinamicidade semiótica.

No entender bakhtiniano, cronotopo se trata da "interligação fundamental das relações temporais e espaciais". Segundo o autor, este termo tem sido empregado pela matemática e pela física, inclusive fazendo parte dos fundamentos da teoria da relatividade de Einstein e foi emprestado por Bakhtin para seus estudos literários e de linguagem "quase como uma metáfora (quase, mas não totalmente)", em função do conceito e expressão da indissolubilidade entre o espaço e o tempo (BAKHTIN, 1988, p. 211). Aqui este conceito aporta uma perspectiva materialista tanto dialética como histórica, em função da porosidade e diálogo do conhecimento com a realidade social em tempos e espaços determinados.

Em "Marxismo e filosofia da linguagem", Bakhtin/ Voloshinov (2010) defendem que a consciência é constituída por signos que adquirem forma e valor definidos coletivamente, conforme as opções ideológicas adotadas durante o acordo entre os sujeitos que compõem um dado social. A consciência, portanto, só se torna o que é quando tomada de conteúdo ideológico (semiótico), e isso ocorre somente durante o processo de convivência social. $\mathrm{Ou}$ 
dito de outro modo: um sujeito só constrói uma visão de mundo a partir de signos que lhe apresentados que fazem sentido para o conjunto de compõe sua consciência. Isso porque nenhuma consciência é vazia e nenhum signo é desprovido de um sentido construído em meio a contexto da convivência social.

Por ideologia, Bakhtin e Voloshinov entendem como "o universo que engloba a arte, a ciência, a filosofia, o direito, a religião, a ética, a política, ou seja, todas as manifestações superestruturais" (FARACO, 2003, p. 46). Qualquer enunciado discursivo, portanto, é para o Círculo sempre ideológico em dois sentidos: a) qualquer enunciado ocorre na esfera de uma das ideologias, ou seja, no interior de uma das áreas da atividade intelectual humana; b) todo enunciado expressa sempre uma posição avaliativa logo, pode-se afirmar que não há enunciado neutro; a própria retórica da neutralidade, para Faraco é também uma posição axiológica (2003, p. 46-47) porque, ao não se posicionar de forma avaliativa, reforça o que está estabelecido como verdade acabada em dado contexto.

De modo semelhante, Miotello (2010, p. 176) aborda a ideologia sob a ótica dos pensadores "como expressão de uma tomada de posição determinada", seja comunicada a partir de uma interpretação da realidade social. Nesse contexto, de acordo com o autor, há sempre a existência do conflito entre a ideologia oficial que é a ideologia hegemônica ou dominante e ideologia do cotidiano que corresponde ao pensamento paralelo, espontâneo, dinâmico, que sempre desafia o sistema dominante.

Sobre a ideologia do cotidiano, diz Bakhtin (2010, p. 88) que ela se refere discurso interior e exterior não estável ou cristalizado socialmente, mas que "é mais sensível, compreensiva, nervosa e móvel que a ideologia enformada, "oficial". No seio da ideologia do cotidiano é que se acumulam aquelas contradições que, após atingirem certo limite, acabam explodindo o sistema da ideologia oficial".

Para Ponzio (2009) e Fiorin $(2006,2008)$ é necessário esclarecer que, embora os conceitos bakhtininos tenham encontrado raízes no Marxismo, a concepção de ideologia proposta é distinta daquela defendida por Marx e Engels. A ideologia é definida por Marx e Engels como uma "falsa consciência dada pela dominação" que faz com quem é dominado veja a realidade invertida, isto é, aqui os sujeitos aceitam e incorporam uma consciência hegemônica por acreditarem que não há outra como alternativa, porque a realidade está dada. Entretanto, pontua Fiorin (2006, p. 29; 32), nem toda ideologia é falsa consciência, porque toda formação ideológica corresponde a um discurso, que, na sua concepção, é um conjunto de temas, de figuras ou de signos em que uma dada visão de mundo se materializa. Com 
efeito, existem discursos dominantes ou ideologias dominantes, assim como existem os discursos dos "dominados" ou ideologias marginais.

A ideologia bakhtiniana estaria realacionada à "expressão das relações históricomateriais dos homens, mas "expressão" não significa somente interpretação ou representação, também significa organização, regulação dessas relações”. A ideologia se configura em

(...) um sistema de concepções que está determinado pelos interesses de um determinado grupo social, de uma classe e que, baseado em um sistema de valores, condiciona atitudes e comportamentos tanto dos sujeitos do grupo em questão como dos outros grupos sociais, quando se converte em ideologia dominante (...) as estruturas e superestruturas se relacionam de uma forma dialética, e os signos são elemento mediador de ambas (...) (PONZIO, 2009, p. 116).

Importante destacar o papel do signo como elemento mediador entre as estruturas e superestruturas, sobretudo no que se refere ao aspecto ideológico como constituinte do próprio signo. Desse modo, o signo trata-se de um produto material, no sentido físico, ao mesmo tempo em que é material "no sentido de que é um produto histórico-social" (PONZIO, 2009, p. 119).

A identificação do ideológico com o semiótico, no entendimento de Faraco (2003, p. 47-48), se refere ao materialismo como fundamento da filosofia da cultura postulada pelo Círculo. O signo, como produto de uma criação ideológica, assim o é, não somente porque é dotado de materialidade física, mas também porque é parte concreta e totalmente objetiva da realidade prática dos seres humanos, não sendo, portanto, desconectado da vida social. E aí estão incluídos todos os tipos de discursos, desde o mais vulgar, que tendem carregar consigo a ideologia do cotidiano, até o mais erudito, como o discurso acadêmico e o discurso científico, que tendem a sustentar a ideologia oficial.

Ao produzir um texto, um discurso ou uma obra, fica difícil dissociar a visão de mundo - que é sempre ideológica - do conhecimento que quer ser compartilhado pelo sujeito-autor. $\mathrm{O}$ conjunto de ideologias aceitas amplamente, aceitas em parte ou rechaçadas por um sujeito no momento em que compõe uma determinada obra é verificado em seu discurso por meio da análise da sua linguagem, seja pela escolha dos termos, ênfases dadas e ordenamento das palavras e argumento. A análise contextualizada da linguagem é objeto da Análise de Discurso, campo de estudo que se dedique a explicar a linguagem do ponto de vista intersubjetivo e sociológico. A própria existência deste campo valida o fato de que a 
linguagem e o discurso tornam qualquer texto necessariamente permeado de conteúdo ideológico.

O movimento "Educação sem partidos", no entanto, defende a ausência de conteúdo ideológico nas escolas por meio da repreensão a professores que façam referências ao cenário político, a partidos políticos e a conceitos e autores considerados doutrinadores, como Marx e Paulo Freire, por exemplo. Para que a transmissão de conhecimento seja plena e efetiva, sugere o movimento que o professor se atenha tão somente à "matéria" a ser transmitida - e não compartilhada - com os alunos nas diferentes disciplinas.

A "matéria" costumeiramente se encontra registrada em textos impressos em livros, apostilas, sites, jornais, etc. Sendo assim, entendem-se como oportunas as seguintes indagações: como é possível separar o discurso do texto ou o texto do discurso? E como é possível separar os conteúdos "racionais" dos ideológicos? Como é possível ler e interpretar textos ou teorias sem lançar mão a visões de mundo e a contextos históricos de quem os conceberam?

Ainda há questões relativas aos processos de transmissão e de compartilhamento do conhecimento. Transmissão ou compartilhamento? Reitera-se com base justamente Freire (2011) que nenhuma consciência é desprovida de conteúdo, por isso ao professor nunca será possível preencher de conteúdo a consciência de um aluno sem que este conteúdo faça sentido com o conjunto de signos que compõe esta consciência, assim como de qualquer sujeito. A educação não pode ser reduzida a um discurso monológico de um professor ou da leitura não interpretativa de um autor impresso em uma apostila. Deve-se levar em consideração o aluno como parte desse processo que é necessariamente dialógico, assim como os processos de transmissão da informação e compartilhamento do conhecimento.

\section{INFORMAÇÃO, CONHECIMENTO E VIDA SOCIAL}

Considera-se que a informação, devido a sua natureza, estável, estocável e a possibilidade que oferece de compreensão mais imediata e pontual, é se transmite. Já conhecimento, se compartilha porque tende de modo mais acentuado à dialogicidade e à alteridade.

Apesar de informação e conhecimento se tratarem de conceitos diferenciados, eles não são isoláveis. O mesmo ocorre em relação aos conceitos os signos e os sinais, de tema e significação abordados por Bakhtin/Volochínov (2010). Para Ponzio (2009, p. 92), o tema é que faz com que o sinal verbal torne-se um signo, porque o relaciona com o contexto social e, 
consequentemente, tornam-se verificáveis as posturas ideológicas constituintes do signo. Já a significação se refere ao estudo do significado de uma enunciação só em relação ao código, ao sistema abstrato da língua, como se fosse independente em relação a seu contexto de enunciação. Aí o signo se reduz ao estado de simples sinal de identificação.

Na visão de Ponzio (2009), a relação dialética entre sinal e signo também é representativa da relação entre o conteúdo explícito e o conteúdo presumido da enunciação. Pois, mesmo que o conteúdo presumido ou interpretado seja mais amplo e complexo por abarcar comportamentos e valorações ideológicas, ele se embasa em elementos estáveis e constantes na vida social, como enunciações com significados explícitos construídos a partir dos recursos linguísticos disponíveis pela língua oficial. O sentido, por conseguinte, resulta no "conjunto dos significados agregados (presumido, incluso, oculto, implícito) que complementam os significados de partida (explícitos)". Somente a partir da relação entre conteúdo presumido e explícito, é que os discursos podem contar com a "objetividade própria de uma materialidade histórica" (PONZIO, 2009, p. 99).

A figura abaixo representa a relação entre sinal e signo, significação e tema e conteúdo explícito e conteúdo presumido, bem como mostra as principais distinções entre esses conceitos para ilustrar a diferença e a complementariedade da informação e do conhecimento.

Quadro 1 - Relação dialética entre sinal e signo, informação e conhecimento.

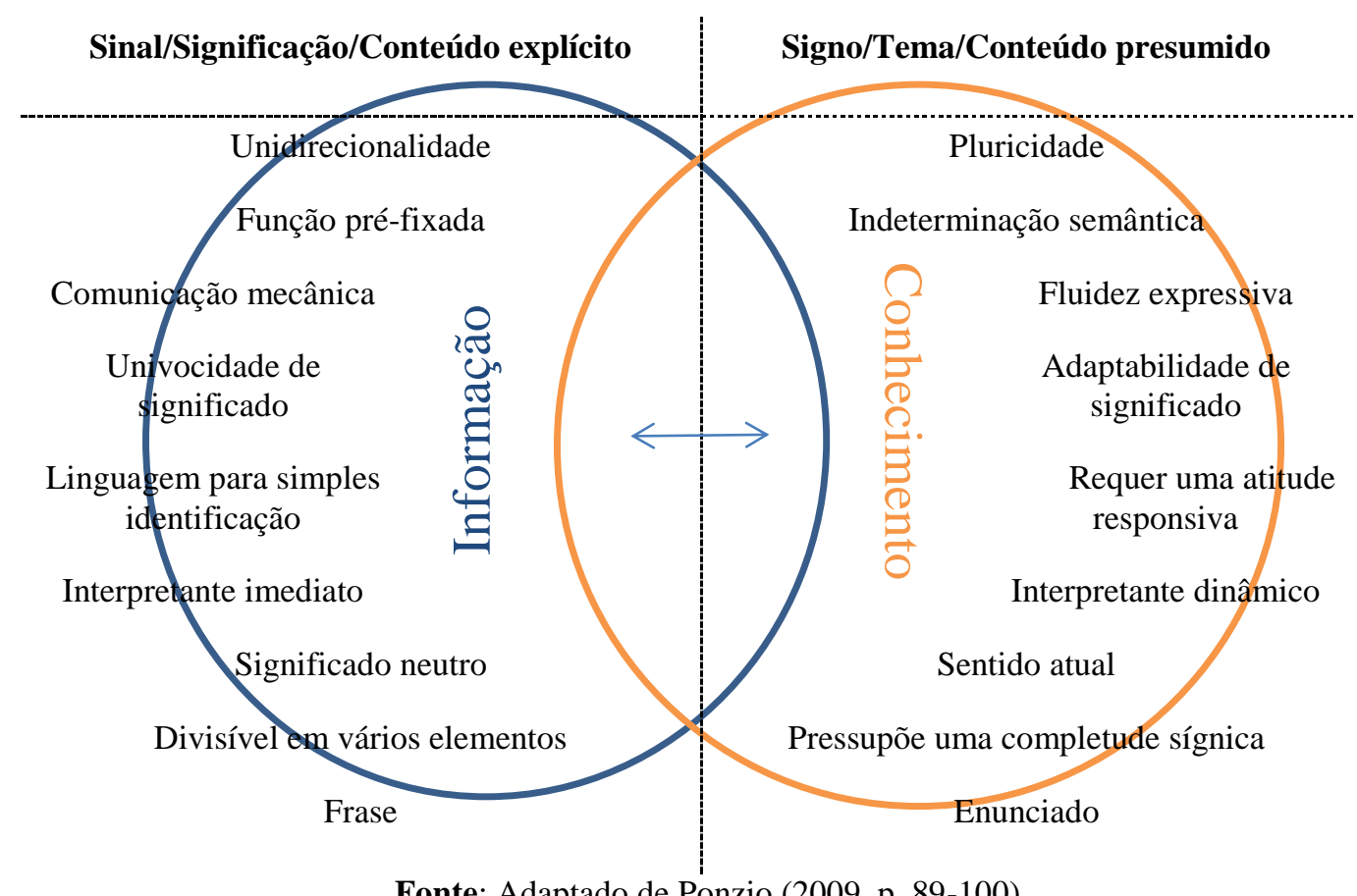

Fonte: Adaptado de Ponzio (2009, p. 89-100) 
A partir do conteúdo exposto na Figura 1 é possível verificar as diferenças e a concomitante indissociabilidade entre as duas esferas. Entretanto, observa-se que o signo/tema/conteúdo/conhecimento presumido sempre absorvem o sinal/significação/conteúdo explícito/informação, reavaliando-os, modificando-os, desconstruindo-os, realocando-os conforme a ocasião, na tentativa de acompanhar as transformações sociais, "suas contradições vivas" e "identidades igualmente provisórias" (BAKHTIN/VOLOCHÍNOV, 2010, p. 141). O sinal e a informação são resultado de uma materialidade física, enquanto que o signo e o conhecimento são resultado de uma materialidade histórica. Todavia, acredita-se que em discurso, toda materialidade física ou registrada é também dotada de uma materialidade histórica.

Mais do que organizar para tão somente recuperar a informação para um determinado uso imediato, a missão das práticas relativas à organização e à representação do conhecimento vislumbra um universo mais amplo. Como já visto anteriormente, isso não significa dizer que a informação e o conhecimento são elementos distanciados e sem relação dialética entre si. Como afirma Barité (2001), o conhecimento se realiza a partir da informação, e ao socializarse, ou seja, ao ser expressado e registrado também se transforma em informação. Com efeito, um sistema de organização e representação do conhecimento, que não deixa de ser também da informação, deve pressupor a dialogicidade entre os autores, os leitores e os profissionais responsáveis a partir de uma dialética entre informação e conhecimento.

Têm-se, com efeito, as atividades de organização e de representação do conhecimento como espaços mediadores de discursos em que a atuação do profissional se evidencia por um conjunto de diálogos eu-outro que se operam em duas dimensões: o "outro- autor do conteúdo" e o "outro-integrante da comunidade", o que necessariamente leva a uma nãoneutralidade do "eu" de quem organiza/representa, cuja ação transcende os limites da racionalidade para que possa chegar a um agir sensível e ético que possa reger de forma polifônica as distintas vozes sociais, inclusive a sua própria voz (ARBOIT, GUIMARÃES, 2015).

No artigo cujo título é a pergunta “What is Knowledge Organization?”, Hjørland (2008b) busca contribuir para o esclarecimento quanto a aspectos relacionados à demarcação do domínio no conjunto do saber. Pondera Hjørland (2008, p. 86-87; 2003 p. 88) que a Biblioteconomia e a Ciência da Informação (CI) são disciplinas centrais da ORC em sentido "restrito", sendo a ORC um campo de estudo que se ocupa da natureza e qualidade dos processos e sistemas de organização do conhecimento, isto é, atividades relativas à descrição 
de documentos, à indexação, à classificação bibliográfica, a bases de dados bibliográficas, a arquivos e a outros tipos de instituições de memória. Por outro lado, Teoria do Conhecimento, Sociologia do Conhecimento, Estudos da Linguagem e Sistemas Simbólicos e a Metafísica são disciplinas centrais da ORC em sentido "amplo", sendo este o domínio que se dedica ao estudo de questões referentes à divisão social do trabalho mental, por exemplo, a organização de instituições de pesquisa e ensino superior, as estruturas de disciplinas e profissões, a organização social da mídia e a produção e disseminação do conhecimento. Para o autor, a ORC em sentido "amplo" se ocupa em resolver questões sobre como a ORC em sentido "restrito" se desenvolve, incluindo aspectos relacionados à produção do conhecimento científico. Com efeito, para Hjørland, mesmo que a ORC tenha duas dimensões, uma não excluí a outra, ao contrário elas têm uma relação de complementaridade e, em função disso, o autor acredita que a ORC se trata de um domínio mais abrangente que a CI por ser seu objeto de estudo o conhecimento de modo geral.

Outro autor que tem se destacado principalmente no campo da CI por defender o seu caráter social é Frohmann. Já no inicio dos anos noventa, o autor parte da crítica ao caráter mentalista da indexação o qual reduz a atividade em uma operação essencialmente intelectual e individual, ou seja, as estruturas cognitivas do indexador são vistas como praticamente as únicas responsáveis por representar o conteúdo de um documento. Assim o indexador é levado pelas estruturas cognitivas a estabelecer índices aos documentos de modo praticamente automático. Para Frohmann (1990, p. 82), isso ocorre em função da crença de que os conceitos são gerados dentro da mente individual e de que qualquer tipo de abstração se trata de um produto de um processo cognitivo. Com base na teoria sobre jogos de linguagem de Wittgenstein, Frohmann (1990) ressalta a necessidade de se construir de modo consistente e explícito regras para indexação a partir da interpretação consciente e socialmente contextualizada do indexador em seu diálogo com o conteúdo expresso nos textos dos documentos. Para tanto, o contexto social de produção e uso da informação deve ser observado uma vez que o autor considera que tanto o produto como o uso é determinado por regras socialmente estabelecidas e, portanto, variáveis, de contexto para contexto.

Como visto anteriormente, o caráter material da informação também tem sido objeto de estudo de Frohmann (2004, 2008), sobretudo no que diz respeito a reforçar o enfoque social da CI e, desse modo, se contrapor ao mentalismo que, para o autor, "privilegia os estudos da informação focados nos indivíduos como agentes de atividades práticas do interesse dos estudos de informação" e, com efeito, "os efeitos sociais e públicos dos sistemas 
de informação tornam-se reféns da questão de quantos indivíduos são afetados". A materialidade da informação, por outro lado, determina seu o caráter social e público, pois uma vez que a informação está materialmente registrada em um documento, ela pode “configurar profundamente a vida social" (2008, p. 21-22). O conhecimento de uma pessoa em sua individualidade torna-se possível somente por meio da Documentação que, por sua vez, contribui para sua inércia, massa e, com efeito, estabilidade do fenômeno científico e para o conhecimento da organização conceitual da ciência (2004, p. 247). Em outras palavras, Frohmann pretende resgatar a importância da Documentação como meio de fixação de conteúdos oriundos de práticas científicas e/ou culturais ligadas ao um contexto histórico e social, onde a informação se materializa para cumprir com a sua função social de compartilhamento do saber.

Pode-se dizer que a defesa da materialidade da informação na contemporaneidade remonta ao conceito de garantia literária postulado por Hulme no início do século $\mathrm{XX}$ (BARITÉ, 2011). Assim como Hulme, Frohmann procura mover o foco da CI novamente para Documentação, uma vez que para ambos os documentos são responsáveis por registrar todo o processo de desenvolvimento do conhecimento, possibilitando desse modo não só a difusão do saber, mas também o entendimento acerca das práticas intelectuais realizadas em diversas épocas e contextos por meio da análise de ocorrências relativas ao uso e/ou ao desuso dos termos (Hulme) ou por meio da análise dos enunciados ou do discurso registrados nos documentos (Frohmann).

Frohmann parte das ideias de Foucault sobre a materialidade dos enunciados, sobre como eles são estabilizados, mantidos nos discursos científicos e, assim, exercem força e poder sobre uma comunidade, como são desestabilizado, decompostos e passam a deixar de existir (2008, p. 22).

Compartilhando similar entendimento acerca do caráter social da ORC, Barité (2001) defende que a finalidade central da ORC é estabelecer conceitos adequados às diversas práticas e atividades sociais vinculadas ao acesso ao conhecimento e, desse modo, operar como instrumento de tratamento e gestão do uso social da informação, procurando abarcar e integrar os fenômenos e as aplicações ligadas à produção, à estruturação, à disposição, ao acesso e à difusão do conhecimento socializado. Para tanto, o objeto de estudo central da ORC deve ser, segundo o autor, o conhecimento socializado.

De acordo com Hansson (2013), o próprio desenvolvimento da web social corrobora de uma forma muito clara para o fato de que a sociedade é a unidade básica de organização do 
conhecimento. Nesse sentido, segundo o autor, a materialidade das atividades de organização do conhecimento se refere a um determinado tipo de influência ideológica que já visto desde a produção social de documentos. O autor cita como exemplo das bibliotecas suecas que em 1921, em função da influência da cultura acadêmica prussiana e suas consequentes e peculiares necessidades práticas e ideológicas, optaram por não adotar a Classificação Decimal de Dewey (CDD) devido a forte discrepância em relação à visão do conhecimento. Entretanto, verifica o autor que em razão da atual desconstrução do bem estar-social e a aplicação do modelo de mercado estadunidense na Suécia, várias bibliotecas, inclusive a nacional, passaram a adotar a CDD a partir de 2008. Atualmente, há na Suécia, segundo o autor, uma iniciativa de implantar uma versão da CDD com alterações alinhadas à visão de mundo sueca.

\section{IMPOSSIBILIDADE DA NEUTRALIDADE NAS ATIVIDADES DE ORC}

As atividades de representação e a organização do conhecimento são vistas como atos não imunes às visões de mundo e ideologias vigentes, pois elas se baseiam em juízos de valor espacial e temporalmente localizados que necessariamente implicam em tomadas de partido. As escolhas de um ou mais signos para representar um documento ou um conceito é sempre feita por meio de apreciação, do contrário, estes seriam atos mecânicos, automáticos passíveis de serem realizados por máquinas. O mesmo ocorre na construção de instrumentos, métodos e sistemas de ORC; todos são elaborados a partir de índices de valor atribuídos de modo consciente por quem os constrói como bem mostram Berman (1993), Olson (2001) e Olson \& Schlegl (2001). Essas atividades e produtos prescindem tanto de aspectos relacionados à racionalidade como aqueles relacionados à ética e à apreciação estética em certos casos, como a representação de obras de arte e/ou conteúdos literários, uma vez que são resultados de uma interpretação específica da realidade.

Com base em uma concepção sociológica, tem se verificado que no domínio de ORC que a neutralidade não é algo considerado possível, uma vez que qualquer signo está sempre ligado ao seu contexto. Assim, durante as atividades de representação e organização do conhecimento não se pode exigir que o classificador/indexador anule suas visões de mundo ou que simulem a inexistência ou o "desligamento" momentâneo da sua consciência. Representar e organizar o conhecimento são atos dialógicos que, por seu turno, sofrem e devem sofrer influências tanto de discursos externos (discurso do autor e discurso dos usuários) quanto de discursos internos (as vozes ideológicas e sociais que compõem a consciência de quem 
representa/organiza), ambos correlacionados entre si; e porque o resultado dos atos de representar e organizar se tratam também de uma resposta aos discursos externos e internos.

Dependendo do domínio a ser coberto, tais relações discursivas são mais perceptíveis, por exemplo, nas ciências sociais e humanas em relação às exatas. Porém, isso não significa que o discurso ideológico esteja completamente ausente nas ciências exatas; o que difere nesse caso é o grau de intensidade e aproximação com o cotidiano que é mais elevado nas ciências sociais e humanas. Todo o processo de produção do conhecimento não é neutro, uma vez que depende especificamente de uma percepção, de uma descrição e de uma avaliação, incialmente de um cientista e posteriormente de um grupo deles que, apesar dos títulos acadêmicos, não deixam de ser sujeitos (ARBOIT, GUIMARÃES, 2015).

Diante das reflexões sobre a presença da subjetividade nas atividades de organização de representação do conhecimento, Hjørland (2008a) oportunamente se pergunta: é a ORC uma atividade neutra? Pode ser? Deve ser? Acredita o autor que a neutralidade não é possível em nenhuma descrição da realidade, pois tal representação é feita a partir de uma avaliação funcional em determinado contexto, ou seja, não somente de modo pragmático, mas também de modo ideológico. Segundo ele, no domínio de ORC essas questões são tradicionalmente tratadas de forma passiva, pois o conhecimento ainda é considerado como o "espelho da natureza".

Habitualmente, os conceitos, por exemplo, têm sido considerados resultados de um processo lógico-cognitivo isolado ocorrido dentro da consciência do ser quando este, por meio da linguagem, qualifica uma determinada substância. Tal qualificação, por sua vez, atribuí características inerentes à substância e, ao mesmo tempo em que revela sua essência a diferencia das demais. Visto que foi com base nessa visão de mundo relacionada à univocidade da substância, que Dahlberg (1978a, 1978b, 1993, 2006) e Wüester (apud CAMPOS, 2001) elaboraram respectivamente a Teoria do Conceito e a Teoria Geral da Terminologia. O conhecimento, a linguagem e o signo linguístico tendem a ser caracterizados como objetos abstratos, autônomos e totalmente desvinculados da prática social e do caráter ideológico que os permeiam. Daí decorre a concepção de linguagem e de conhecimento como sendo naturais e, portanto, neutros, uma vez que se acredita que sua formação ocorre sem as interferências das relações coletivas.

Em relação à subjetividade e a ética informacional, Frohmann (2008) sustenta que a ética está sempre envolvida nas deliberações morais que ocorrem durante as relações entre sujeitos. A subjetividade, portanto, é vista como o cerne da ética, sobretudo na área 
informacional. Nesse sentido, o autor propõe a análise do discurso como método de ensino e pesquisa por se tratar de uma iniciativa que privilegie uma visão analítica, critica e logo não neutra dos processos de produção e uso da informação vista como discursos socialmente construídos (FROHMANN, 1994, 2001).

Considera-se que os julgamentos de valor estão inexoravelmente ligados a qualquer ato responsivo, especialmente aos relacionados às atividades de representação e organização do conhecimento. Esses atos não são indiferentes às vozes sociais que são afetadas por eles. Contudo, ao invés do esforço de neutralização, o que se reivindica é um esforço para que todas as vozes sociais envolvidas participem do processo, conforme postula García Gutierrez (2002) quando sugere a adoção da "ética transcultural de medição". Para que isso ocorra, compreende-se que o classificador/indexador não pode privilegiar uma voz em detrimento da outra nem tampouco anular qualquer uma delas, inclusive aquelas que habitam a sua própria consciência, buscando o exercício da polifonia durante a realização dos atos de representação e organização do conhecimento.

O profissional de ORC, com efeito, passaria de um omisso colaborador da ideologia hegemônica, escondido por detrás da máscara da neutralidade, a um agente participante e colaborador de um processo democrático, que não suplanta e nem ignora nenhuma postura ideológica envolvida, inclusive a sua. Mais do que isso: além de participar ativamente do processo assumindo uma postura ideológica, atua como regente das demais vozes sociais, sobretudo aquelas relacionadas à produção e ao uso do conteúdo representado e organizado. Para tanto, é necessário que o profissional pratique o princípio da alteridade para se aproximar o máximo possível do outro, entender seus interesses, suas necessidades. Obviamente que é impossível ver o mundo tal qual o outro o vê, mas, é possível, por meio do excedente de visão que o "eu" tem em relação ao "outro", o eu simular o outro, no sentido compreendê-lo para melhor representá-lo. Ao mesmo tempo, os aspectos cronotópicos devem ser levados em consideração, pois, como já visto, o "outro", assim como o "eu”, são também produtos de uma determinada época e lugar.

Sobre a neutralidade profissional, Jensen (2006) constata que em uma sociedade onde há concentração de poderes e luta de classes esta e qualquer outro tipo neutralidade é impossível. Mesmo a escolha pela neutralidade é, na verdade, uma tomada de posição política não explícita que serve apenas para reforçar a ideologia dominante. Ou seja, segundo o autor, a ideologia da neutralidade política condiciona profissionais e cidadãos a não reconhecer e, ao mesmo tempo, manter as relações de poder existentes na sociedade. Optar pela neutralidade, 
segundo Jensen, trata-se de nutrir uma ilusão que leva somente a estagnação intelectual e a ruína do debate político em prol de reivindicações necessárias em todas as esferas da vida social.

Observa-se que a atitude ética e democrática do profissional, em consonância com o pluralismo ou pluripartidarismo social faz-se necessária, de modo a se buscar o exercício de uma polifonia, uma equipolência de vozes sociais em um determinado contexto. Essa posição que exige que o profissional tome decisões relativas aos processos de organização e representação do conhecimento decorre da competência atribuída ao classificador/indexador pela sociedade, espaço em que se verifica a natureza dinâmica do conhecimento. Durante o exercício dessa atribuição, é conferido ao profissional um poder de nomear (OLSON, 2002). A partir daí, pressupõe-se que o profissional tenha legitimidade para atuar como representante dessa coletividade em matéria de organização e representação do conhecimento, mesmo que não detenha um conhecimento profundo acerca do saber que atende. Entretanto, considera-se que apenas ter esse poder não seja o suficiente. Como um regente de uma orquestra, o profissional, por meio do constante diálogo com a comunidade que atende, deve ser capaz articular os signos representativos de todas as vozes envolvidas em benefício dessa mesma coletividade que o elegeu como representante.

Aliando-se a essa concepção sociocultural, há de se mencionar, ainda, as preocupações de Beghtol $(2002,2005)$ acerca da necessidade de as linguagens de indexação imbuírem-se de uma efetiva garantia cultural, encontrando lastro na realidade social a que se destinam, em que os instrumentos de representação do conhecimento apoiam-se na linguagem como produto representativo de uma realidade social e, portanto, devendo representar o contexto cultural dessa realidade.

Ainda que o domínio de ORC conte com vozes dissidentes, identifica-se certa carência de um posicionamento ético sensível às necessidades de conhecimento das mais diversas vozes sociais, a partir de uma atuação que respeite a diversidade e o pluralismo lógico e cultural. Tal estado é evidenciado pelo escasso desenvolvimento dos métodos, das técnicas e das ferramentas existentes para organizar o conhecimento em toda sua pluralidade. Conforme García Gutiérrez $(2007,2011)$ e Hansson (2013), isso se deve em parte à incorporação massiva e acrítica de artefatos oriundos das novas tecnologias de informação e à crença na qual a mera aplicação dessas tecnologias resolveria todos os problemas de produção, organização e acesso ao conhecimento. Nesse sentido, orientado pela busca de soluções que visem a uma pragmática contextual, o García Gutiérrez apresenta as seguintes propostas: a 
adoção de uma teoria de conceitos abertos e inacabados, a prática bem fundamentada da desclassificação por meio do estabelecimento de dois operadores que se complementam mutuamente: o operador complexo, que trabalha para garantir de modo igualitário a expressão de todas as posições e cosmovisões a respeito de um tema; e o operador transcultural que, por sua vez, decide e executa democraticamente a partir de um consenso ampliável, obrigatória e periodicamente revisado, uma síntese transcultural baseada no levantamento realizado pelo operador complexo. O operador transcultural seria o antídoto para o relativismo do qual poderia ser acusado o operador complexo e este, por outro lado, representaria o equilíbrio democrático e hermenêutico no qual o operador transcultural busca respaldo (GARCÍA GUTIÉRREZ, 2007, 2011; GARCÍA GUTIÉRREZ; MARTÍNEZ-ÁVILA, 2014).

\section{CONSIDERAÇÕES FINAIS}

Do exposto, verifica-se que a linguagem utilizada e registrada em qualquer domínio de conhecimento ao longo do tempo incorpora necessariamente concepções ideológicas. Tal interpretação se sustenta nas ideias bakhtinianas sobre o processo dialógico da linguagem e do signo linguístico. Um termo, um conceito, um discurso, um texto reflete e refrata ideologias presentes em determinado ambiente social. Em razão disso, defende-se que as noções bakhtinianas de signo e discurso sejam levadas em consideração tanto no estudo como na prática de ORC, como alternativa para romper com posturas voltadas para neutralidade, tanto das noções dialética de informação e conhecimento como da própria atuação profissional.

Tanto a produção, a interpretação, a leitura, a representação e a organização de informação e conhecimento necessariamente sofrem influência de discursos externos e internos impregnados de ideologia. Esses discursos entram em contato no momento da representação, que constitui uma resposta a quem participa do processo de produção e uso do conhecimento e aos eventuais conflitos entre eles existentes. Isso faz com que o profissional de ORC assuma uma postura de mediador de conhecimento, onde é requerida a capacidade de transcender sua identidade em busca de um novo ponto de vista com base na necessária interferência do outro. Assim, os termos, códigos e demais signos que compõem os sistemas de organização e representação do conhecimento assumem uma "representatividade dialógica e dinâmica", pois não apenas devem corresponder ao conteúdo dos documentos e serem capazes de dialogar com a comunidade usuária, em um dialogismo da linguagem que pressupõe a alteridade dos sujeitos como consequência da alteridade das situações sociais. 
Para tanto, faz-se necessário o reconhecimento da não procedência de uma visão neutra ou "sem partidos" em relação à informação, ao conhecimento e, com efeito, às atividades de representação e organização. O profissional de ORC, mesmo no exercício da sua função, não deixa de ser um sujeito dotado de uma consciência intersubjetiva resultante de um processo sociocognitivo, que necessariamente age no mundo em função do seu álibi em não existir, adquirindo em virtude da posição que ocupa a responsabilidade de projetar sistemas e realizar atividades de organização e representação do conhecimento de forma dialógica e polifônica.

Dispensando o esforço de neutralidade o profissional se tornará capaz de, por um lado, identificar suas posições enquanto sujeito único e insubstituível e, por outro, conhecer suas posições enquanto sujeito representante de uma determinada comunidade de produção e uso do conhecimento. Para tal, ele deverá conhecer os diversos partidos presentes no sistema de conhecimento ao qual faz parte, valendo-se do seu excedente de visão que adquire a partir da convivência no ambiente em que residem estas vozes sociais como condição de bem representá-los, buscando o modo mais polifônico, democrático e pluripartidário possível. Do contrário, opta-se pela insistência em permanecer reproduzindo de modo acrítico a ideologia dominante. 


\section{REFERÊNCIAS}

ARBOIT, A.; GUIMARÃES, J. A. C. The ethics of knowledge organization and representation from a bakhtinian perspective. Knowledge Organization, v. 42, n. 5, p. 324$331,2015$.

BAKHTIN, M. Estética da criação verbal. São Paulo: Saraiva, 2011.

Formas de tempo e de cronotopo no romance. BAKHTIN, M. Questões de literatura e de estética (a teoria do romance). São Paulo: Unesp, 1988. p. 211-349. Manuscrito de 1973 publicado postumamente.

Para uma filosofia do ato responsável. São Carlos: Pedro e João, 2010. Manuscrito de 1920-1924 publicado postumamente.

BAKHTIN, M (VOLOCHÍNOV). Marxismo e filosofia da linguagem. 14. ed. São Paulo: Hucitec, 2010. Publicado originalmente em 1929.

BARITÉ, M. Organización del conocimiento: un nuevo marco teórico-conceptual en Bibliotecología y Documentación. In: CARRARA, K. (Org.). Educação, universidade e pesquisa. Marília: Unesp-Marília-Publicações, 2001. p. 35-60.

La garantía literaria como herramienta de revisión de sistemas de organización del conocimiento: modelo y aplicación. 2011. 360 f. Tese (Doutorado em Información Científica) - Facultad de Comunicación y Documentación. Universidad de Granada, 2011.

BEGHTOL, C. A. proposed ethical warrant for global knowledge representation and organization systems. Journal of Documentation, v. 58, n. 5, p. 507-532, 2002.

Ethical decision-making for knowledge representation and organization systems for global use. Journal of the American Society for Information Science and Technology, v. 56, n. 9, p. 903-912, 2005

BERMAN, S. Prejudices and antipathies: A Tract on the LC Subject Heads Concerning People. 2. ed. Jefferson; NC; London: McFarland, 1993.

CAMPOS, M. L. A. Linguagem documentária: teorias que fundamental sua elaboração. Rio de Janeiro: EdUFF, 2001.

DAHLBERG, I. Fundamentos teóricos-conceituais da classificação. Revista de Biblioteconomia de Brasília, v. 6, n. 1, p. 9-21, jan./jun. 1978a. 11-19, 2006.

Knowledge organization: a new science? Knowledge Organization, v. 33, n. 1, p.

. Knowledge organization: its scope and possibilities. Knowledge Organization, v. 20, n. 4, p. 211-222, 1993.

Teoria do conceito. Ciência da Informação, v. 7, n. 2, p. 101-107, 1978 b. 
FARACO, C. A. Linguagem e diálogo: as idéias lingüísticas do círculo de Bakhtin. Curitiba: Criar, 2003.

FIORIN, J. L. Linguagem e ideologia. 8. ed. São Paulo: Ática, 2006.

Introdução ao pensamento de Bakhtin. São Paulo: Ática, 2008.

FREIRE, Paulo. Pedagogia da autonomia: saberes necessários à prática educativa. 43. ed. São Paulo: Paz e Terra, 2011.

FROHMANN, B. Rules of indexing: a critique of mentalism in information retrieval theory. Journal of Documentation, v. 46, n. 2, p. 81-101, jun. 1990.

Deflating information: from science studies to documentation. Toronto; Buffalo: University of Toronto Press, 2004.

O caráter social, material e público da informação. In: FUJITA, M.; MARTELETO, R.; LARA, M. (Orgs). A dimensão epistemológica da ciência da informação e suas interfaces técnicas, políticas e institucionais nos processos de produção, acesso e disseminação da informação. São Paulo: Cultura Acadêmica; Marília: Fundepe, 2008, p. 1934.

Discourse analysis as a research method in library and information science. Library and Information Science Research, v. 16, p. 119-138, 1994.

Discourse and documentation: some implications for pedagogy and research. Journal of Education for Library and Information Science, v. 42, n. 1, p. 12-26, 2001.

Subjectivity and information ethics. Journal of the American Society for Information Science and Technology, v. 59, n. 2, p. 267-277, 2008.

GARCÍA GUTIÉRREZ, A. Desclasificados: pluralismo lógico y violencia de la clasificación. Barcelona: Anthropos, 2007.

Epistemología de la documentación. Barcelona: Stonberg, 2011.

Knowledge organization from a "culture of the border": towards a transcultural ethics of mediation. In: LÓPEZ-HUERTAS, M. J. (Ed.). Challenges in knowledge representation and organization for the 21st century: integration of knowledge across boundaries. Würzburg: ERGON-Verlag, 2002. p. 516-522.

GARCÍA GUTIÉRREZ, A.A .L.; MARTÍNEZ-ÁVILA, D. M. Critical Organization of Knowledge in mass media information systems. Knowledge Organization, v.41, n.3, p. 205216, 2014.

GUIMARÃES, J. A. C. Aspectos éticos em organização e representação do conhecimento (O.R.C.): uma reflexão preliminar. In: Maria Nélida González de Gomez; Evelyn Goyannes Dill Orrico. (Org.). Políticas de memória e informação: reflexos na organização do conhecimento. Natal: EDUFRN, 2006, , p. 237-264 
A dimensão teórica do tratamento temático da informação e suas interlocuções com o universo científico da International Society for Knowledge Organization (ISKO). Revista Ibero-americana de Ciência da Informação, v. 1, n. 1, p. 77-99, jan./jun. 2008.

JENSEN, R. The myth of the neutral professional. Progressive librarian, n. 24, p. 28-34, $2004 / 2005$.

HANSSON, J. The materiality of Knowledge Organization: epistemology, metaphors and society. Knowledge Organization, v. 40, n. 6, p. 384-391, 2013.

HJØRLAND, B. Deliberate bias in knowledge organization? In: Arsenault, C.; Tennis, J. T. (Ed.). Culture and Identity in Knowledge Organization: Proceedings of the Tenth International ISKO Conference, Montréal, 5-8 August 2008. Würzburg: ERGON, 2008a. p. 256-261.

. What is knowledge organization (KO)? Knowledge Organization, v. 35, n. 2/3, p. 86-101, 2008b.

LÓPEZ-HUERTAS, M. J. Cultural impact on knowledge representation and organization in a subject domain. In: In: ARSENAULT, C.; TENNIS, J. T. (Eds.). Culture and identity in knowledge organization: Proceedings of the Tenth International ISKO Conference (Montréal, Canadá, August 5-8, 2008. Advances in knowledge organization, n. 11. Würzburg: Ergon Verlag, 2008. p. 340-346.

MIOTELLO, V. Ideologia. In: BRAIT, B. (Org.). Bakhtin conceitos-chave. 4. ed. São Paulo: Contexto, 2010. p. 167-176.

OLSON, H. A. The power to name. Dordrecht: Kluwer, 2002.

OLSON, H. A.; SCHLEGL, R. Standardization, objectivity, and user focus: a meta-analysis of subject access critiques. Cataloging \& Classification Quarterly, v. 32, n. 2, p. 61-80, 2001.

PONZIO, A. A concepção bakhtiniana do ato como dar um passo. In: BAKHTIN, M. Para uma filosofia do ato responsável. São Carlos: Pedro e João, 2010. p. 9-38.

A revolução bakhtiniana: o pensamento de Bakhtin e a ideologia. São Paulo: Contexto, 2009. 